course, we would not find microscopic blood; but in my experience I have, in a large number of cases, found microscopic blood after painstaking investigation.

Another point is in regard to reflex anuria which follows cases in which there is a single impacted stone on one side. It has been my experience in those cases in which there is anuria lasting three, five, and, in one case, ten days, that we will, on careful and repeated roentgen-ray examinations, find an impacted stone on the other side. In every case in which there have been bilateral calculi reflex anuria has not been found present. In those cases, I believe, we should make repeated searches to locate the stone on the other side. One of my old preceptors, Professor Israel, laid particular stress on this point, and in two cases I believe we were able to save the patients' lives. Where there is complete anuria differentiated from nephritis, in nephritis we will at least have a teaspoonful of urine excreted; that is, we will not have in any nephritic condition a complete and absolute anuria; and so by remembering this point $I$ was able, in two cases of ureteral calculus in which experts had made a diagnosis of nephritis with complete suppression of urine, to find bilateral ureteral calculi.

Dr. Edward L. Young, Jr., Boston: Dr. Bugbee's trick of coiling a ureter catheter around a stone is a very pretty trick and a great help. provided it comes out all right. One case in connection with it might perhaps serve as a warning in the use of the procedure $-\mathbf{a}$ case in which a ureteral stone was hooked in that fashion, but then the fisherman was not able to bring in the fish, and for over an hour tried to get the catheter out. So I think there is a warning in regard to the use of the ureter in that condition, on account of the possibility of breaking off the catheter and also of getting the catheter up and having it caught there.

I wanted to emphasize what has been already emphasized, the indefiniteness of symptoms in the majority of cases of renal stone. Also, typical symptoms do appear, including blood and pus, without any calculus being present, and especially the symptom of pain. I think all statistics of pain in connection with calculus show that it is almost always indefinite and often misleading.

I have not looked up the cases at the Massachusetts General Hospital in regard to crossed symptoms, but I can only remember having seen two cases within a comparatively recent time, and I should like to register my opinion that a damaged kidney on one side without any symptoms, and a normal kidney on the other which seems to have the symptoms, is a comparatively rare condition. I do not mean that symptoms may not be mainly on the undamaged or slightly damaged side, but I think a normal kidney on one side showing symptoms and a damaged kidney on the other not showing any symptoms is, at least in my experience, rare.

Then the question of the removal of ureteral stones without operative procedure which has been spoken of so enthusiastically by every one today-I do not know whether we in Boston are slower than the rest of you in making a diagnosis, or less skilful in the use of the operating cystoscope, but we see large ureteral stones that I am convinced it would be impossible to remove by any method short of the open operation. Likewise, we fail to get stones of moderate size out in a percentage of cases larger than that spoken of today.

\section{SPINAL PUNCTURE IN DIABETES INSIPIDUS}

EVARTS A. GRAHAM, M.D.

Fellow of the American College of Surgeons; Surgeon, Park Hospital MASON CITY, IOWA

Since the discovery by Magnus and Schaefer ${ }^{1}$ in 1901 of the diuretic action of extracts of the posterior lobe of the hypophysis, attention has been directed to that organ as an important factor in the causation of diabetes insipidus. Frank, ${ }^{2}$ in an important article published in 1912, reviewed the literature then existing on the subject and made a strong plea for a consideration of the relationship between the hypophysis and diabetes insipidus. Numerous writers already had emphasized the fact that lesions of the brain which involved the vicinity of the hypophysis were often accompanied by polyuria without sugar. Oppenheim, ${ }^{3}$ in thirtysix cases of basal syphilitic meningitis, observed polyuria in twelve. Two of these showed at necropsy a gumma of the optic chiasm and hypophysis. Kruse, ${ }^{3}$ in a study of thirty cases of bitemporal hemianopsia, observed diabetes insipidus in seven; and Spanbock and Steinhaus ${ }^{3}$ mention its occurrence in eleven of fifty cases of bitemporal hemianopsia. Polyuria a s s o ciated with metastatic carcinoma involving the hypophysis or its region, secondary to carcinoma of the breast, is a fairly frequent occurrence. Cases have been reported by Simmonds, ${ }^{4}$ Rosenhaupt, ${ }^{5}$ Miller ${ }^{6}$ and von Gierke.? $\mathrm{R}$ e c e n $\mathrm{t} l \mathrm{y}$ Sekiguchi ${ }^{8}$ has described two additional cases. Cushing's experiments in 1913 led him to conclude that there was a strong "argument in favor of the view that an actual disturbance of the pituitary body itself, rather than the stimulation of some predicated diuretic center in the remote third ventricle surmounting the growth, was the inciting cause of a condition worthy of the designation of diabetes insipidus." Lewis and Matthews ${ }^{10}$ in 1913 concluded from their experiments that diabetes

1. Magnus and Schaefer: The Actions of Pituitary Extract Upon the Kidney, Jour. Physiol., 1901, 1902.

2 Kidney, Jour. Physiol, 19uingen der Hypophyse insipidus, Berl. klin. Wchnschr., 1912, 49, 393 .

3. Quoted by Frank (Note 2).

4. Simmonds: Hypophysi

5. Rosenhaupt, H.: Berl. klin. Wchnschr., 1903, p. 893.

6. Miller, J. L.: The Relation of the Hypophysis to Certain Clinical Manifestations and the Therapeutic Applications of Its Extract, Am. Jour. Med. Sc., 1916, 152, 549.

7. Von Gierke, E.: Hypophysis und Epiphysis bei Diabetes insipidus, Verhandl. d. deutsch. path. Gesellsch., 1914, 17, 200.

8. Sekiguchi: Hypophysial Disorder in Mammary Cancer and Its Relation to Diabetes Insipidus, Ann. Surg., 1916, 63, 297.

9. Cushing, Harvey: Concerning Diabetes Insipidus and the Polyurias of Hypophyseal Origin, Boston Med. and Surg. Jour., 1913,

168, 901 . Lewis, D., and Matthews, S. A.: The Pars Intermedia: Its Rela tion to Diabetes Insipidus, Tr. Path. Soc. Chicago, 1913, 9, 16. 
insipidus is probably dependent on the hypersecretion of the diuretic substance of the posterior lobe which is secreted by the epithelial covering known as the pars intermedia. Falta, ${ }^{11}$ however, warns against a too hasty conclusion that lesions of the base of the brain which induce polyuria do so always by mediation of the hypophysis, although he discusses at length the possibility that such may be the case.

Several cases of diabetes insipidus of which the onset occurred after a trauma to the head are in the literature. Doubtless, at least a temporary polyuria will be found to be very common after head injuries, especially basal skull fractures, if attention is more frequently directed to the output of urine. Mohr ${ }^{\mathbf{1 2}}$ has recorded a case which developed about three weeks after a basal skull fracture, and Kleeblatt ${ }^{13}$ has described one occurring on the third day after a similar lesion. French and Ticehurst ${ }^{\mathbf{1 4}}$ also observed a case of diabetes insipidus which had its origin in a fracture (through the sphenoid). Recently I have seen a case of fracture of the skull in which the roentgenogram clearly revealed the line of fracture extending into the sella turcica (Fig. 3). During the first twenty-four hours the amount of urine passed was 40 ounces $(1,280$ c.c. $)$. During the second day the total amount increased to 130 ounces (4,160 c.c.), and on the third day 110 ounces ( 3,520 c.c.) were passed. Two days later the total output had returned to normal. At no time did the urine show any abnormal constituent. $\mathrm{I}^{15}$ have recently reported another case in which a total output of 170 ounces $(5,500$ c.c.) was passed during a twenty-four hour period, following a gunshot wound of the head which severed the optic nerves, probably at the chiasm, with probable resultant injury to the hypophysis. This urine was of a specific gravity of only 1.002 , and contained no sugar.

The suggestion of the hypophysial origin of diabetes insipidus led somewhat empirically to the employment of extracts of hypophysis therapeutically. Numerous cases are now in the literature reporting markedly beneficial results, especially when the extract has been given intravenously and also even when given hypodermically. Recently Hoppe-Seyler ${ }^{16}$ has reported a case of a man, aged 25 , with diabetes insipidus who had no evidence of syphilis and no roentgen evidence of any lesion of the hypophysis. Hypodermic injections of hypophysis extract, however, resulted in the restoration of the amount and concentration of the

11. Falta: The Ductless Glandular Diseases, Philadelphia, P. Blakiston's Son \& Co., Ed. 2, p. 322.

12. Mohr: Diabetes Insipidus nach Schädelgrundbrüche, Monatsschr. f. Unfallheilk., $1912,19,362$.

13. Kleeblatt: Diabetes insipidus nach Schädelverletzungen, Med. Klin., 1915, 11, 915

14. French, H., and Ticehurst, C. B.: Relation of Traumatic Diabetes Insipidus to Glycosuria, Tr. Clin. Soc., London, 1906, 39, 117.

15. Graham, E. A.: Diabetes Insipidus as a Sequel to a Gunshot Wound of the Head, Ann. Surg., 1917.

16. Hoppe-Seyler: Beziehung des Diabetes insipidus zum Hypophyse und seine Behandlung mit Hypophysenextrakt, München. med. Wchnschr., 1915, 62. urine to normal. When given by the mouth, no appreciable effect was noticeable. The administration of atropin diminished the volume of urine, but also kept back the solids, whereas with hypophysis extract the solids appeared in normal concentration despite the marked reduction in volume. He considers that the therapeutic results are as striking as those obtained in the treatment of myxedema with thyroid extract. Konschegg and Schuster ${ }^{17}$ have also reported an instructive case in which the administration of hypophysis extract to a patient with diabetes insipidus resulted in a return of the urinary conditions and of the water intake to normal. They report that the findings here are in contrast to those obtained when the extract is administered to normal individuals. With the latter, following the injection the decrease in the excretion of water is accompanied by a decrease in the concentration of the solids.

The case reported below is of great interest, not only because it illustrates a type of diabetes insipidus probably induced by disturbance of the hypophysis through an increased pressure of cerebrospinal fluid, but also because the relief of pressure by spinal puncture was immediately followed by a cessation of the polyuria and other symptoms. So far as I have been able to learn from the literature, there has been only one other case of diabetes insipidus in which spinal puncture was made. That was a case reported by $\mathrm{J}$. B. Herrick $^{18}$ in 1912. In that case the lumbar puncture was made simply for the purpose of obtaining some spinal fluid and with no idea of improving the symptoms; - but following the puncture, the amount of uirine dropped from 10 liters to 1 liter, and the specific gravity correspondingly changed from 1.001 to 1.031 .
June 22, 1916, a man, aged 24, consulted me because of dizziness, headache, extreme thirst and the passing of enormous quantities of urine. He stated that, March 13, while at work in a cement plant, he sustained an injury to his chest as a result of being accidentally struck with an iron bar. He thinks he was unconscious for a few minutes, although he knows of no injury to the head. He stopped work and went home, but was not compelled to go to bed. A physician told him that he had a fracture of the sternum and of two ribs on the left side. He reported for work on the next evening, but was sent home again and remained away from his work until April 4. Within a day or two after the injury he noticed that he was markedly constipated so that he could hardly get a bowel movement even with cathartics. He had no headache nor dizziness until after he resumed work. Then during the first week of April, he began to notice severe headache and dizziness every day. These symptoms became progressively worse. The headache was chiefl; frontal and in the temporal regions, and also sometimes "behind the eyes." It was described as resembling sharp, cutting pains, sometimes going up through the ears. Headache was always worse after

17. Konschegg and Schuster: Deutsch. med. Wchnschr., 1915, 61, 1091 .

18. Herrick, J. B.: Report of a Case of Diabetes Insipidus with Marked Reduction in the Amount of Urine Following Lumbar Punc
ture, Arch. Int. Med., July, 1912, p. 1 . 
excitement or hard muscular work. It was not always present all day. Nausea and vomiting were rarely present, but when nausea did occur, it was always worse at breakfast time. Reading always aggravated the dizziness. No disturbance in power of vision had been noted. The only relief possible from the headache and dizziness was in lying down.

Beginning with the latter part of April, marked polyuria set in. This became progressively worse up to the time I first saw him. During this time he had to get up at night to urinate, frequently as often as six times. During the day he passed urine as often as every hour or half hour. At each act of urination he passed enormous quantities of urine, without pain or burning. He never measured accurately the amount of urine passed in twenty-four hours, but he estimated it as high as 10 or 12 quarts daily. During a period of a little more than an hour while I was examining him, he passed more than a quart. His thirst was insatiable, but his appetite was poor. It was not accompanied by a craving for any special kind of food, such as carbolyydrates. He thinks he lost about 25 pounds after his injury.

His previous history was negative except for measles in childhood. He denied any venereal infection. $\mathrm{He}$ is the father of a healthy child 1 month old. His family history likewise was of no special importance. His father and mother were both alive and well, the father at 70 years, and the mother at 66 . $\mathrm{He}$ is one of nine brothers and sisters, all of whom are well.

The examination revealed a fairly well nourished young man who seemed bright and intelligent. Physical examination showed no abnormality of any kind. His vision and eyegrounds were examined by Dr. F. G. Murphy, who reported no abnormality. The blood was practically normal, and the systolic pressure was $120 \mathrm{~mm}$. The urine was clear, slightly acid and of a light straw color. Its specific gravity was 1.001 . It contained no albumin or sugar, and practically no sediment except an occasional urate crystal and an epithelial cell. A roentgen examination of the skull revealed a very marked narrowing of the upper margin of the sella turcica (Fig. 1). The distance between the anterior and posterior clinoid processes was only about $2 \mathrm{~mm}$., whereas the normal should be from 10 to $14 \mathrm{~mm}$. He was advised to enter the hospital for several days for examination, but he declined to do so. I then advised that lie come to the hospital on the following day for a lumbar puncture and to remain for a few days later. He consented to do so; and on the following day, June 24, lumbar puncture was performed with novocain anesthesia. Immediately after the insertion of the needle into the spinal canal, fluid shot out in a steady stream for a distance of from 8 to 12 inches. Because of the sudden surprising gush, some of the fluid was lost; but a little more than half an ounce was saved. The fluid was still running in a steady stream; but because of fear of too suddenly lowering the intraspinal pressure, the needle was withdrawn. He immediately stated that his headache and dizziness were entirely gone. despite the fact that they had been pronounced before the puncture was made. He was then put to bed; but about four hours later without our knowledge or consent he got up, dressed himself, and walked home, a distance of about a mile from the hospital. On examination the fluid was found to be clear and of a pale straw color. After it was centrifuged, the sediment was found to contain only two cells (mononuclear in type) and no bacteria. It was intended to save some of the fiuid for a Wassermann test, but through a mistake in directions it was thrown away. A Wassermann test of the blood, however, was negative.

Because of the brief stay in the hospital it was impossible to make any quantitative studies of the urine; but it is interesting that during the four hours in the hospital no urine passed, the longest interval without urination since the onset of the symptoms. The subsequent history is of great interest. For the next four days after leaving the hospital he suffered with intense headache and dizziness to such an extent that he was bedridden, but the polyuria and thirst remained absent. $\mathrm{He}$ passed urine at this time only four or five times within the twenty-four hours. He then returned to the hospital and stayed for five days. During this time the headache and the dizziness gradually disappeared. The volume of urine passed during the twenty-four hours varied between 1 and 2 liters. and its specific gravity varied between 1.020 and 1.028. At no time did it show any abnormal constituent.

September 18, we saw the patient again. He stated then that he had been working since the middle of July. He thought he drank a normal quantity of water and passed a normal quantity of urine. Since the spinal puncture he had not had to urinate once during the night; and during the day he passed urine only three or four times. He had gained 5 pounds since leaving the hospital, but still felt dizzy at times. He stated that in the morning he feit perfectly well, but about the middle of the afternoon began to develop a little headache and dizziness, which continued until his evening meal. Then he would feel well again. $\mathrm{He}$ attributed the onset of headache and dizziness chiefly to exhaustion from work.

\section{COMMENT}

The apparent chain of events in this case is probably as follows: In some unknown way the accident led to an increase in the amount of intraspinal fluid. This in turn led to symptoms suggestive of intracranial pressure, such as headache and dizziness; and the hypopilysis was so affected that poly-
induced. The immediate uria without sugar was induced. The immediate
improvement of all the symptoms after the lumbar improvement of all the symptoms after the lumbar
puncture is striking. The question of how the spinal fluid became so much increased cannot be satisfactorily answered. The roentgen-ray findings are interesting, but probably should not be taken as conclusive evidence that the sella turcica was narrowed to the extent of producing pressure on the hypophysis. Although the normal distance between the anterior and posterior clinoid processes varies between 10 and $14 \mathrm{~mm}$., it is possible for the processes to be actually fused without any appreciable change in the volume of the sella and without any symptons of pressure, as repeatedly verified at necropsy. Figure 2 shows how, owing to the roughly hexagonal form of the sella turcica in the horizontal plane, the clinoid processes may be actually fused without producing any diminution in volume of the sella. The case here reported tends to support the view of the relationship existing between disturbances of the hypophysis and diabetes insipidus.

An immediate striking relief of symptoms has been obtained by the performance of spinal puncture. 